\title{
Pelebaran Jalan Ruas Jembatan Penanggungan - Batu Ampar (No. 354) Menggunakan Perkerasan Kaku Di Kecamatan Guluk-Guluk Kabupaten Sumenep
}

\author{
Road Widening of Jembatan Penanggungan - Batu Ampar (No. 354) Using \\ Rigid Pavement at Guluk-Guluk Sub District, Sumenep District
}

\author{
Ahmad Suwandi ${ }^{1}$, Dewi Widi Astutik ${ }^{2}$ \\ ${ }^{1}$ Program Studi Teknik Sipil, Fakultas Teknik, Universitas Wiraraja, Jl. Raya Sumenep Pamekasan Km 5 \\ Patean, Sumenep. Kode pos 69451. Email : suwandyach@wiraraja.ac.id \\ ${ }^{2}$ Program Studi Teknik Sipil, Fakultas Teknik, Universitas Wiraraja, Jl. Raya Sumenep Pamekasan Km 5 \\ Patean, Sumenep. Kode pos 69451. Email : dewi76121@gmail.com
}

\begin{abstract}
Abstrak
Prasarana jalan yang baik merupakan sesuatu kebutuhan yang diharapkan oleh masyarakat dan merupakan faktor penunjang lancarnya perekonomian, ekonomi, sosial dan budaya, dimana kurangnya kapasitas jalan akan menyebabkan ketidaknyamanan kepada pengguna jalan. Mengingat kondisi ruas jalan jembatan penanggungan - batu ampar kurang maksimum dalam memberikan pelayanan sehingga diperlukan adanya peningkatan jalan atau pelebaran jalan guna memenuhi kebutuhan lalu lintas yang semakin meningkat di kecamatan Guluk-Guluk Kabupaten Sumenep. Maka diperlukan perencanaan dalam pembangunan/pelebaran pada ruas jalan jembatan penanggungan - batu ampar pada kanan kiri jalan tersebut. Daerah manfaat jalan yang ada dilapangan hanya 6,0 $\mathrm{m}$ sehingga pelebaran pada kanan kiri jalan direncanakan menggunakan perkerasan kaku/beton. Dari hasil survey di lapangan didapat LHR 26200 smp, nilai CBR 3,84\%, pertumbuhan kendaraan 2\% dan direncanakan Kuat Tekan Karakteristik yang direncanakan Beton (f'c) 25 Mpa, berdasarkan hasil perhitungan menggunakan metode Bina Marga tahun 2003 didapat tebal lapis pondasi bawah 10,0 cm dan tebal struktur perkerasan beton $22,0 \mathrm{~cm}$.
\end{abstract}

Kata Kunci : Perkerasan Kaku; LHR; CBR

\begin{abstract}
A good road infrastructure is a need which society expected and a supporting factor for the smooth economic matters, economy, social and culture, where the lack of road capacity will cause the road users feel inconvenience. Recalling that the condition of the road-section isn't maximumly works in providing services so that requires for road improvement or road widening to fulfill increased traffic needs in Guluk guluk sub-distric, sumenep district. So it's need a plan to development/widening penanggungan-batu ampar bridge road-section on the left and right side of the road. Road benefits area is only 6,0 $\mathrm{m}$ so that the widening on the right and left side of the road be planned to use concrete stone pavement. From the survey results, obtained LHR $26200 \mathrm{smp}$, CBR score $3,84 \%$, vehicle growth $2 \%$, and be planned the characteristic of compressive strength is concrete stone ( $\left.f^{\prime} c\right) 25$ Mpa. Based on counting result used the bina marga metode year 2003, found that bottom-foundation layer thickness is 10,0 cm and concrete-stone structure thickness is 22,0 cm.
\end{abstract}

Keyword : Rigid pavement; LHR; CBR 


\section{PENDAHULUAN}

Seiring dengan pesatnya pertumbuhan ekonomi dibutuhkan kelancaran dalam peningkatan prasarana transportasi. Salah satu prasarana penting bagi kelancaran perekonomian adalah perencanaan prasarana transportasi. Tidak selalu kebutuhan manusia tersedia dalam jarak dekat. Majunya peradaban, kebutuhan manusia semakin meningkat dan beragam.

Untuk melayani dan mendukung pergerakan manusia tersebut diperlukan sarana dan prasarana transportasi yang memadai, tanpa adanya prasarana transportasi yang baik perpindahan barang dan jasa. Prasarana utama bagi pembangunan suatu wilayah, baik daerah perkotaan maupun pedesaan adalah pembangunan jalan, jembatan serta sarana-sarana lain yang membantu kelancaran arus lalu lintas.

Kurangnya kapasitas jalan yang menghubungkan antara kecamatan Ganding - Guluk-Guluk menyebabkan ketidaknyamanan bagi para penggunan jalan, sehingga lalu lintas antar pengguna jalan kurang lancar. Hal ini dikarenakan lebar badan jalan yang ada dilokasi 4,0 m, maka dari itu, dibutuhkan pembangunan pelebaran jalan yang memadai agar dapat memberikan pelayanan yang optimal kepada pengguna jalan sesuai dengan kebutuhan kapasitas jalan, serta dapat memberikan kenyamanan dan keamanan bagi masyarakat di daerah tersebut.

Tidak lupa juga Infrastuktur adalah sebagai tanggung jawab dari pemerintah daerah setempat yang dimana untuk kelancaran aktifitas publik sebagai sistem perencanaan pembangunan daerah yang merata dan semua bisa merasakan akan adanya perkembangan. Infrastuktur yang akan dibahas disini meliputi jalan, oleh jalan dan saluran tersebut.

Dengan seiring berjalannya waktu juga dan kemajuan pada zaman ini, tidak dipungkiri bahwa kehidupan dimasyarakat juga semakin meningkat, dari segi kebutuhan rumah tangga, akses mobilisasi dalam beraktifitas, kelayakan hidup pada lingkungan meliputi kebersihan dan perkembangan Infrastruktur yang cukup memadai di masyarakat tersebut.

\section{METODE}

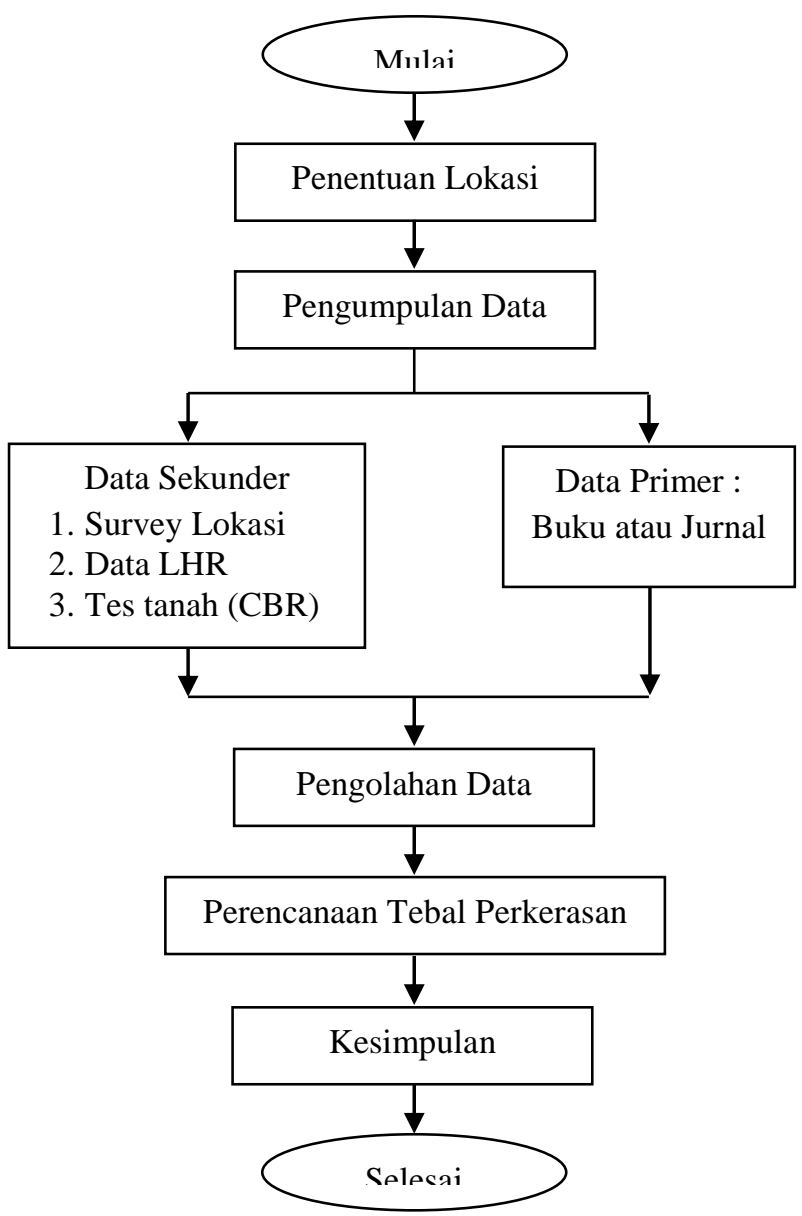

Gambar 1. Diagram Alir Perancangan Aplikasi Perhitungan RAB

Pada penelitian ini akan direncanakan pelebaran pada sisi kanan jalan 1,0 m dan sisi kiri jalan 1,0 m dengan panjang 1000 meter. Konstruksi digunakan yakni Perkerasan jalan dengan Beton Bersambung tetapi Tanpa Tulangan, pemilihan konstruksi ini berdasarkan lahan yang tersedia kurang memadai.

\section{HASIL DAN PEMBAHASAN}

\section{Data Perencanaan}

Lebar badan jalan $\quad: 4,0 \mathrm{~m}$

Daerah manfaat jalan $\quad: 6,0 \mathrm{~m}$

Umur rencana : 20 Tahun

Pertumbuhan lalu lintas : $2 \%$

Jenis jalan

: Kolektor

Tipe jalan
: 2 lajur 2 arah (Tidak

Berbagi) 


\section{Data CBR Tanah}

Hasil CBR lapangan :

$\begin{array}{ll}\text { STA 0 } \pm 000 & =4,55 \% ; 3,77 \% \\ \text { STA 0+250 } & =6,25 \% ; 7,09 \% \\ \text { STA 0 }+500 & =4,89 \% ; 6,05 \% \\ \text { STA 0+750 } & =5,01 \% ; 4,74 \% \\ \text { STA } 1 \pm 000 & =4,20 \% ; 3,84 \%\end{array}$

Tabel 1. Persen (\%) yang Sama atau Lebih Besar

\begin{tabular}{ccc}
\hline CBR & $\begin{array}{c}\text { Jumlah yang } \\
\text { sama atau } \\
\text { lebih besar }\end{array}$ & $\begin{array}{c}\text { Persen }(\%) \\
\text { yang sama } \\
\text { atau lebih } \\
\text { besar }\end{array}$ \\
\hline 3,77 & 10 & 100 \\
3,84 & 9 & 90 \\
4,20 & 8 & 80 \\
4,55 & 7 & 70 \\
4,74 & 6 & 60 \\
4,89 & 5 & 50 \\
5,01 & 4 & 40 \\
6,05 & 3 & 30 \\
6,25 & 2 & 20 \\
7,09 & 1 & 10 \\
\hline
\end{tabular}

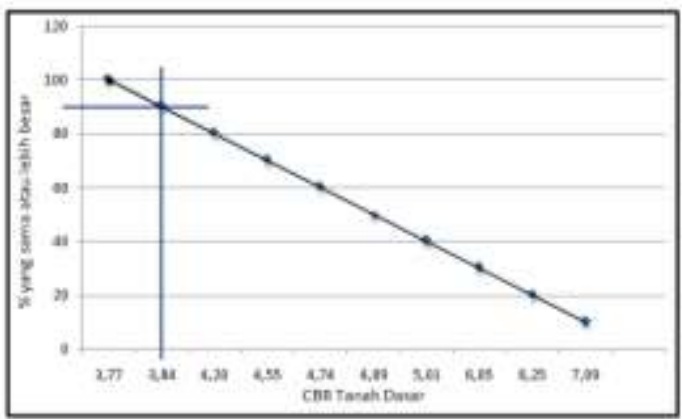

Gambar 2. Grafik Penentuan Nilai CBR

Dari grafik di atas diperoleh nilai CBR tanah dasar $=3,84 \%$

\section{Data Lalu Lintas}

Tabel 2. Data Lalu Lintas Harian

\begin{tabular}{cccc}
\hline Jenis & $\begin{array}{c}\text { Volume } \\
\text { Kendaraan }\end{array}$ & \multicolumn{2}{c}{$\begin{array}{c}\text { Beban Sumbu } \\
\text { Kendaraan }\end{array}$} \\
Depan & $\begin{array}{c}\text { Belaka } \\
\text { ng }\end{array}$ \\
\hline SM & 24719 & 1 & 1 \\
MP & 591 & 1 & 1 \\
PICK-UP & 584 & 1 & 1 \\
TRUCK & 38 & 3 & 6 \\
BUS MINI & 9 & 1 & 1 \\
Kend. Tak & 259 & 1 & 1 \\
Bermotor & & & \\
\hline
\end{tabular}

Umur rencana (UR)

:20 Tahun

Pertumbuhan lalu lintas (i) : $2 \%$

Tipe jalan

: 2 lajur 2 arah (Tidak Berbagi)
Koefisien Distribusi (C) : 0,50

Tabel 3. Perhitungan Jumlah Sumbu Kendaraan Berdasarkan Jenis dan Bebannya

\begin{tabular}{|c|c|c|c|c|c|c|c|c|c|c|c|}
\hline \multirow{2}{*}{$\begin{array}{c}\text { Jenis } \\
\text { Kendaraan }\end{array}$} & & $\begin{array}{l}\text { Kol } \\
\text { Beb }\end{array}$ & $\begin{array}{l}\text { ffigura } \\
\text { in Sum } \\
\text { (ton) }\end{array}$ & & $\begin{array}{l}\text { Jumlah } \\
\text { Kendara }\end{array}$ & $\begin{array}{c}\text { Jumlah } \\
\text { Sumbu } \\
\text { Per }\end{array}$ & $\begin{array}{c}\text { Jumla } \\
\mathrm{h}\end{array}$ & \multicolumn{2}{|c|}{ STRT } & \multicolumn{2}{|c|}{ STRG } \\
\hline & RD & $\mathrm{RB}$ & RGD & RGB & an & $\begin{array}{c}\text { Kendara } \\
\text { an }\end{array}$ & $\mathrm{u}$ & BS & JS & BS & JS \\
\hline SM & 1 & 1 & - & - & 24719 & - & - & - & - & - & - \\
\hline MP & 1 & 1 & - & - & 591 & - & - & - & - & - & - \\
\hline Pick-Up & 1 & 1 & - & - & 584 & - & - & - & - & - & - \\
\hline Truck & 3 & 6 & - & - & 38 & 2 & 76 & 3 & 38 & 6 & 38 \\
\hline Bus Mini & 1 & 1 & - & - & 9 & - & - & - & - & - & - \\
\hline $\begin{array}{l}\text { Kend. Tak } \\
\text { Bermotor }\end{array}$ & 1 & 1 & - & - & 259 & - & - & - & - & - & - \\
\hline \multicolumn{7}{|c|}{ TOTAL } & 76 & - & 38 & - & 38 \\
\hline
\end{tabular}

Faktor pertumbuhan lalu lintas (R) dihitung dengan rumus :

$$
\mathrm{R}=\frac{(1+\mathrm{i})^{\mathrm{UR}}-1}{\mathrm{i}}=\frac{(1+2 \%)^{20}-1}{2 \%}=24,30
$$

Jumlah Sumbu Kendaraan Niaga (JSKN) selama umur rencana (20 Tahun) yaitu :

$$
\begin{aligned}
& \text { JSKN }=\text { JSKNH } \times 365 \times \mathrm{R} \\
& =76 \times 365 \times 24,30 \\
& =6,74 \times 10^{5} \\
& \begin{aligned}
\text { JSKN rencana } & =6,74 \times 10^{5} \times \mathrm{C} \\
& =6,74 \times 10^{5} \times 0,5 \\
& =337000 \\
& =3,37 \times 10^{5}
\end{aligned}
\end{aligned}
$$

Repetisi Beban Sumbu

Tabel 4. Perhitungan Repetisi Sumbu Rencana

\begin{tabular}{ccccccc}
\hline \multirow{2}{*}{$\begin{array}{c}\text { Jenis } \\
\text { Sumbu }\end{array}$} & $\begin{array}{c}\text { Beban } \\
\text { Sumbu } \\
\text { (ton) }\end{array}$ & \multicolumn{6}{c}{$\begin{array}{c}\text { Jumlah Proporsi Proporsi } \\
\text { Sumbu }\end{array}$} & Beban & Sumbu & $\begin{array}{c}\text { Lalu } \\
\text { Lintas } \\
\text { Rencana }\end{array}$ & $\begin{array}{c}\text { Repetisi } \\
\text { Yang } \\
\text { Terjadi }\end{array}$ \\
\hline STRT & 3 & 38 & 1 & 0,5 & 337000 & 168500 \\
Total & $\mathbf{3 8}$ & $\mathbf{1}$ & & & \\
STRG & 6 & 38 & 1 & 0,5 & 337000 & 168500 \\
Total & $\mathbf{3 8}$ & $\mathbf{1}$ & & & \\
Kumulatif & 76 & & 1 & & 337000 \\
\hline
\end{tabular}

Perhitungan Tebal Pelat Beton

- Jenis Perkerasan : Perkerasan Beton Bersambung Tanpa Tulangan (BBTT)

- Jenis Bahan : Beton

- Umur Beton : 28 Hari

- Kuat Tekan Karakteristik Beton (f'c) : $25 \mathrm{Mpa}$ $=250 \mathrm{~kg} / \mathrm{cm}^{2}$

Menggunakan angregat batu pecah, maka :

- $\mathrm{F}_{\mathrm{cf}}{ }=\mathrm{K}\left(\mathrm{f}^{\prime} \mathrm{c}\right)^{0,50}$ 


$$
\begin{aligned}
& =0,75(25)^{0,50} \\
& =3,75 \mathrm{Mpa}
\end{aligned}
$$

- $\mathrm{JSKN}=337000$

- Faktor Keamanan Beban (Fkb) : 1,0

Menentukan nilai CBR efektif, tebal pondasi bawah dan taksiran tebal pelat

- CBR Tanah Dasar : 3,84\%

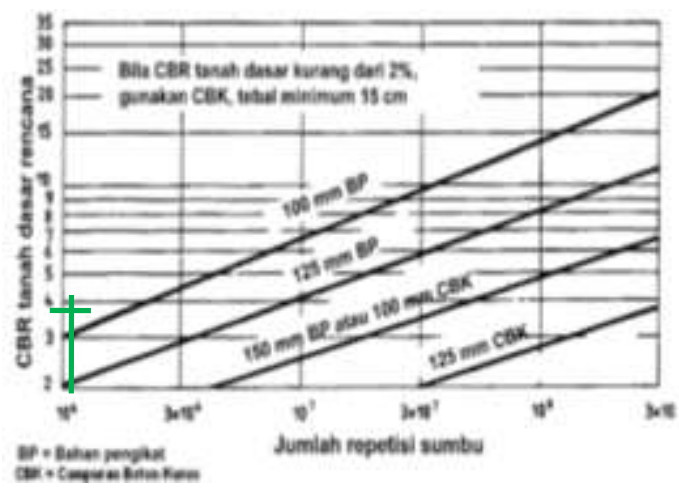

Gambar 3. Grafik Tebal Pondasi Bawah Minimum Untuk Perkerasan Beton Semen

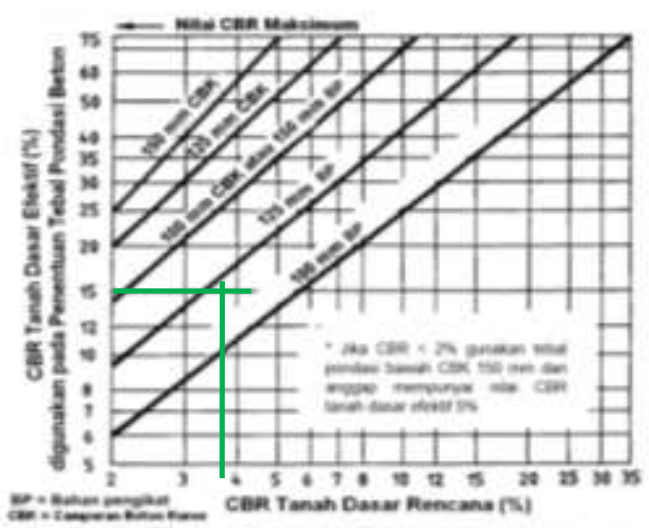

Gambar 4. Grafik CBR Tanah Dasar Efektif dan Tebal Pondasi Bawah

- CBR Efektif : $15 \%$

- Tebal lapis pondasi bawah menggunakan LeanMix Concrete, tebal $10 \mathrm{~cm}$

- JSKN : $337000=0,337 \times 10^{6}$

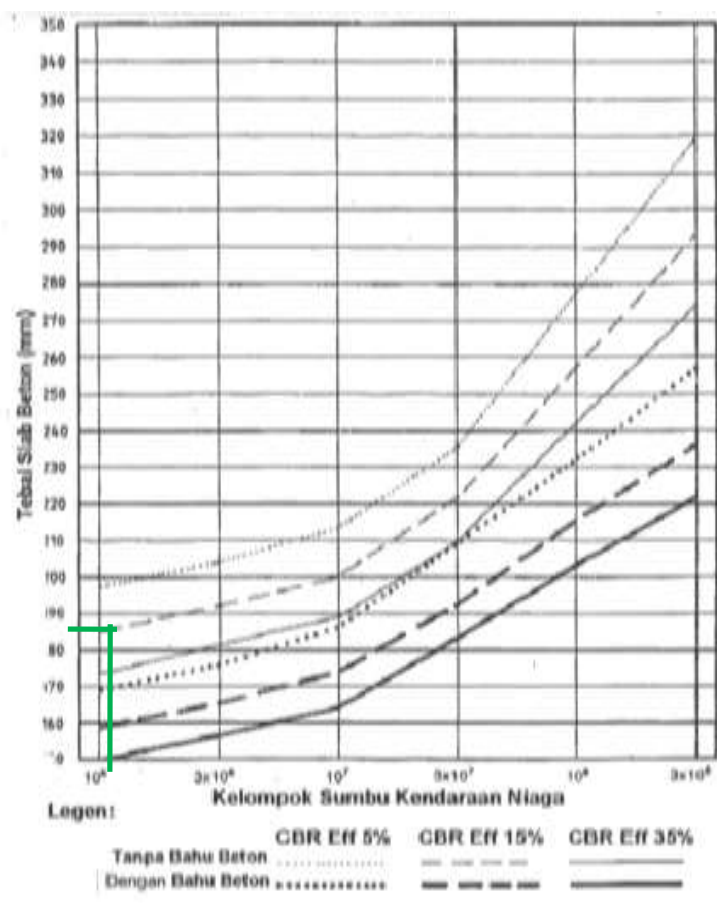

Gambar 5. Grafik Perencanaan Tebal Taksiran Pelat Beton

Tabel 5. Analisa Fatik dan Erosi untuk tebal pelat

\begin{tabular}{|c|c|c|c|c|c|c|c|c|}
\hline \multirow[b]{2}{*}{$\begin{array}{l}\text { Jenis } \\
\text { Sumbu }\end{array}$} & \multicolumn{4}{|c|}{ Beban } & \multicolumn{2}{|c|}{ Analisa Fatik } & \multicolumn{2}{|c|}{ Analisa Erosi } \\
\hline & $\begin{array}{c}\text { Beban } \\
\text { Sumbu } \\
(\mathrm{kN})\end{array}$ & $\begin{array}{l}\text { Rencan } \\
\text { Per } \\
\text { Roda } \\
(\mathrm{kN})\end{array}$ & $\begin{array}{c}\text { Repetisi } \\
\text { yang } \\
\text { Terjadi }\end{array}$ & $\begin{array}{c}\text { Faktor } \\
\text { Tegangan } \\
\text { dan Erosi }\end{array}$ & $\begin{array}{c}\text { Repetisi } \\
\text { Ijin }\end{array}$ & $\begin{array}{c}\text { Persen } \\
\text { Rusak } \\
(\%)\end{array}$ & $\begin{array}{l}\text { Repetisi } \\
\text { Ijin }\end{array}$ & $\begin{array}{c}\text { Persen } \\
\text { Rusak } \\
(\%)\end{array}$ \\
\hline & & & & $\mathrm{TE}=0,88$ & & & & \\
\hline STRT & 30 & 15 & 168500 & $\begin{array}{l}\mathrm{FRT}=0,23 \\
\mathrm{FE}=2,30\end{array}$ & TT & 0 & TT & 0 \\
\hline STRG & 60 & 30 & 168500 & $\begin{array}{l}\mathrm{TE}=1,44 \\
\mathrm{FRT}=0,38 \\
\mathrm{FE}=2,90\end{array}$ & $10^{6}$ & 16,9 & $10^{6}$ & 16,9 \\
\hline \multicolumn{5}{|c|}{ TOTAL } & 16,9 & $<100 \%$ & 16,9 & $<100 \%$ \\
\hline
\end{tabular}
$22 \mathrm{~cm}$ 


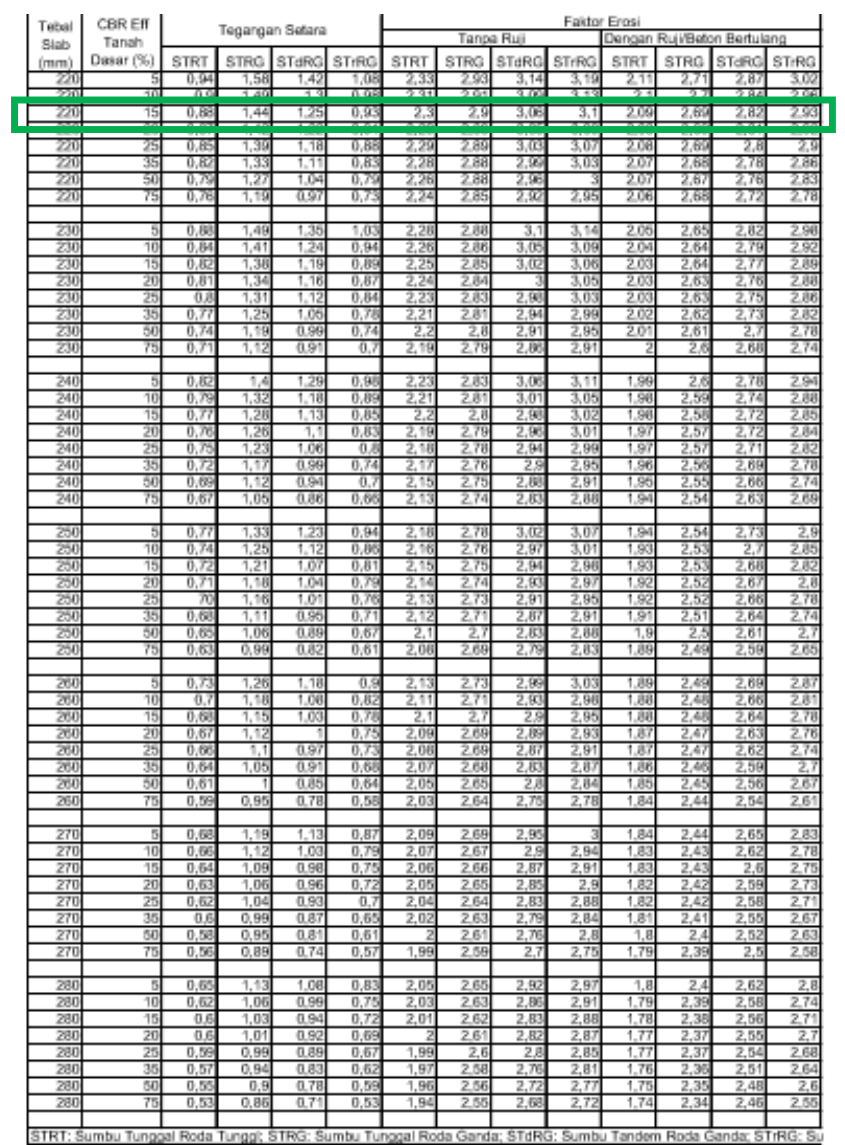

Gambar 6. Tegangan Ekivalen dan Faktor Erosi untuk Perkerasan Tanpa Bahu Beton

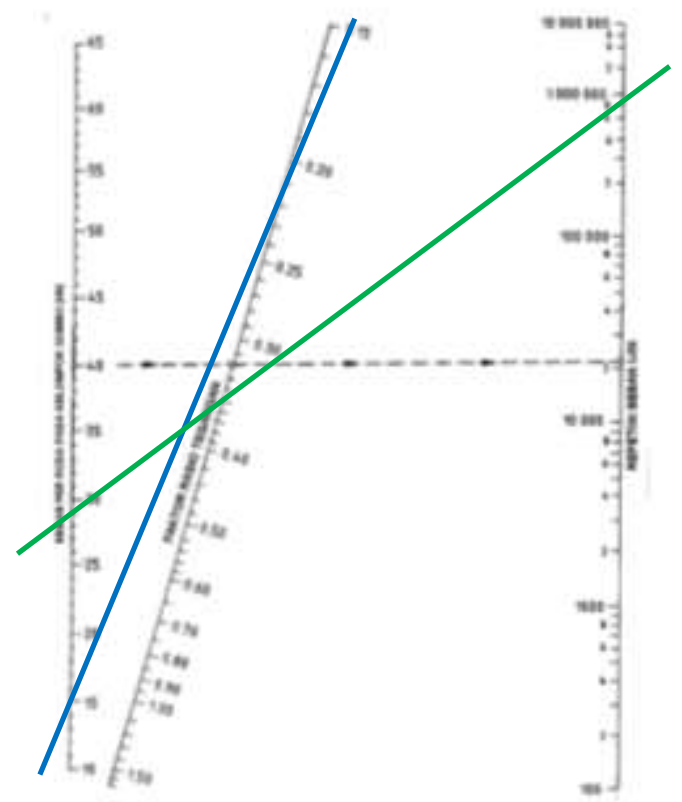

Gambar 7. Analisis Fatik dan Beban Repetisi Ijin Berdasarkan Rasio Tegangan, Dengan/Tanpa Bahu Beton

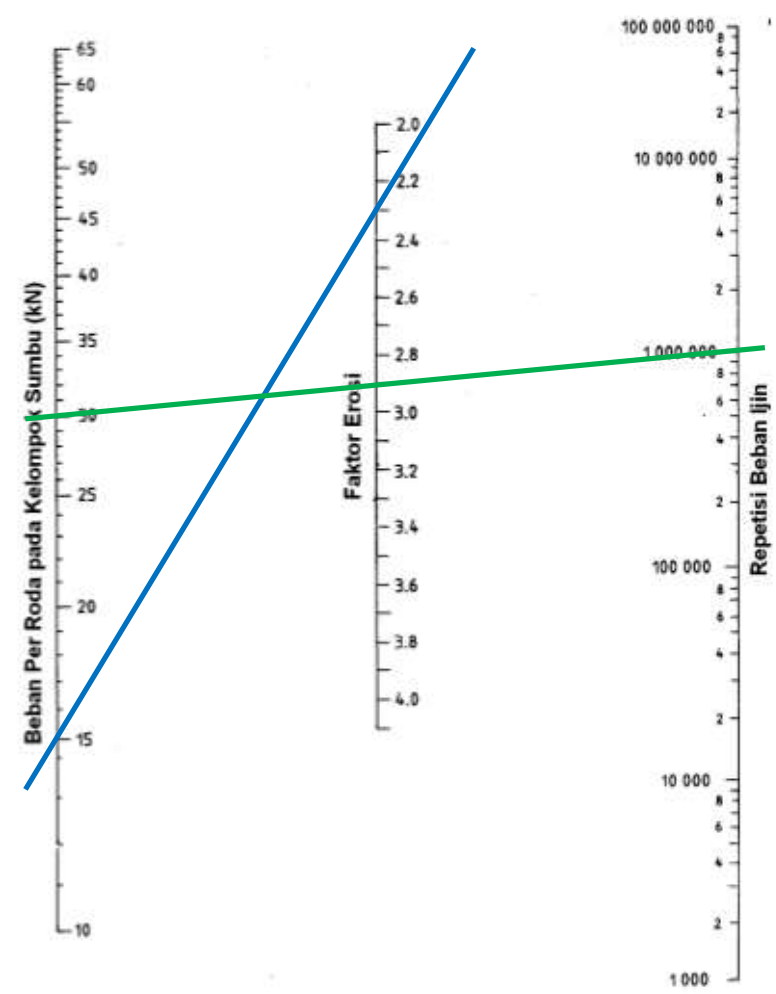

Gambar 8. Analisis Fatik dan Beban Repetisi Ijin Berdasarkan Rasio Tegangan, Dengan/Tanpa Bahu Beton

Dari hasil perhitungan di dapat tebal plat $22 \mathrm{~cm}$.

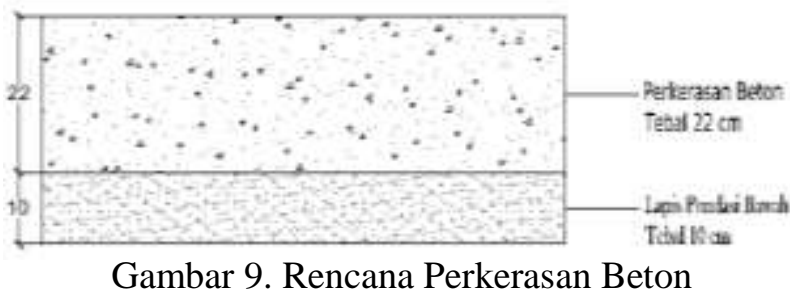

\section{KESIMPULAN}

Berdasarkan hasil perhitungan dengan metode Bina Marga 2003 pada ruas jalan Jembatan Penanggungan - Batu Ampar Kecamatan Gulukguluk Kabupaten Sumenep dengan menggunakan perkerasan $\mathrm{kaku} / \mathrm{beton}$ didapat tebal lapis pondasi bawah $10 \mathrm{~cm}$ dan tebal struktur perkerasan beton 22 $\mathrm{cm}$.

\section{REFERENSI}

Direktorat Jenderal Bina Marga Direktorat Bina Jalan Kota (BINKOT), Manual Kapasitas Jalan Indonesia. 1997. Jakarta, Bina Karya

Hardiyatmo, Hary Christady. 2011. "Perancangan Perkerasan Jalan dan Penyelidikan Tanah". Yogyakarta, Universitas Gadjah Mada.

Hera Ambarwati, Vinandita. 2014. "Perkerasan Jalan Raya". Tugas Kuliah. Malang, Politeknik, Universitas Negeri Malang.

Proteksi/Desember 2020 Volume 2 No. 2 
Nikmah, Ainun. 2013. "Perencanaan Perkerasan Kaku (Rigid Pavement)". Tugas Akhir, Semarang, Fakultas Teknik, Universitas Negeri Semarang.

Pd-T-14-2003. 2003. "Perencanaan Perkerasan Jalan Beton semen". Departemen Pemukiman dan Prasarana Wilayah.
Peraturan Pemerintah RI Nomor 43 Tahun 1993." Prasarana dan Lalu Lintas Jalan".

Sukirman, Silvia. 1999. "Dasar-Dasar Perencanaan Geometrik Jalan", Nova, Bandung.

Undang-Undang Republik Indonesia Nomor 38 Tahun 2004 tentang jalan. 